\title{
Model predictive control of multilevel cascaded converter with boosting capability - experimental results
}

\author{
P. WIATR* and A. KRYŃSKI \\ Electrotechnical Institute, 28 Pożaryskiego St., 04-703 Warsaw, Poland
}

\begin{abstract}
The main goal of this paper is to present a five-level converter with the feature of output voltage boosting capability. Thanks to its modular construction and single DC source usage, 5LCHB converter becomes an important alternative for two-level converters operating with DC-DC converters that use bulky inductors. Furthermore, model predictive control (MPC) method is presented, which allows for boosting output voltage of presented converter while providing three-phase load current control and flying capacitor voltage stabilization. The last section describes a $5 \mathrm{kVA}$ laboratory model of five-level hybrid converter interfacing RL load and shows experimental results confirming theoretical analysis derived in previous sections.
\end{abstract}

Key words: cascaded H-bridge (CHB), model predictive control (MPC), multilevel converters.

\section{Introduction}

Multilevel converters, by overcoming classical topologies limitations and presenting considerable advantages to typical twolevel converters, have gained a lot of interest in academic and industrial world in recent years. This paper is a continuation of the simulation study published in [1]. Many papers with new multilevel topologies and their control have been presented. There are also industrial applications like electric drives ACS2000 by ABB [2] and ALSPA VDM6000 by ALSTOM [3], static synchronous compensators PCS 6000 STATCOM by ABB [2], TMEiC solar inverters SOLAR WARE 630 [4] and Eaton 93PM UPS [5].

Multilevel converters are well suited for medium-voltage and high power application because of connecting switching devices in series and using several lower voltage DC levels to synthesize a staircase output voltage waveform.

Such converter design gives advantages such as:

- lower output voltage distortion (lower),

- lower switching losses,

- lower $\frac{d V}{d t}$ in output voltage,

- reduced switching frequency for a given current distortion,

- reduced input filter size for the grid connected applications.

Three main topologies within multilevel converter family are $[6,7]$ :

- diode clamped converter (NPC),

- flying capacitor (FC),

- cascaded H-bridge converter (CHB).

Recently, a new family called modular multilevel converters (MMC) gained popularity thanks to its attractive features in high power applications [8-10].

*e-mail: p.wiatr@iel.waw.pl

Manuscript submitted 2017-04-05, revised 2017-06-02, initially accepted for publication 2017-06-28, published in October 2017
By applying modifications to classic multilevel converter topologies, another branch called hybrid converters was created.

Hybrid converters integrate more than one converter topology into one. Each new topology has its own advantages and drawbacks and suits a certain application.

The following examples of hybrid converter topologies can be listed out:

- 5L-HNPC - cascaded connection of 3L-NPC converter [11],

- ANCP-5L - 3L-NPC converter connected with 3L-FC converter [12],

- 3L-NPC connected with H-bridge [13],

- 5L-MLC ${ }^{2}-[14]$

This paper presents an investigation of a novel hybrid converter topology - five-level cascaded H-bridge converter (5LCHB) with only one DC source and model predictive controller (MPC). According to $[1,15]$ this converter brings the following features:

- generation of boosted output voltage,

- good quality of output waveform with low THD,

- fast response to reference current change.

Utilization of the model predictive controller (MPC) for $5 \mathrm{LCHB}$ converter was tested in $[1,15]$. The advantages of MPC control can be summed up as follows:

- simple solution for multilevel converter compared to other control strategies,

- elimination of PWM modulator,

- simple implementation of capacitor voltage balancing.

Among the disadvantages of the MPC control we may list:

- requirement of fast processor for on-line optimization,

- the knowledge of the load parameters.

Previous publication concerning 5LCHB converter with MPC control used only simulation model [1, 15-17]. This work examines $5 \mathrm{kVA}$ laboratory model of $5 \mathrm{LCHB}$ with the MPC control. 


\section{5LCHB converter model}

The 5LCHB converter topology is shown in Fig. 1. The proposed converter uses a standard three-leg two-level converter and a H-bridge in series with each converter leg. Each H-bridge uses a capacitor as a DC power source.

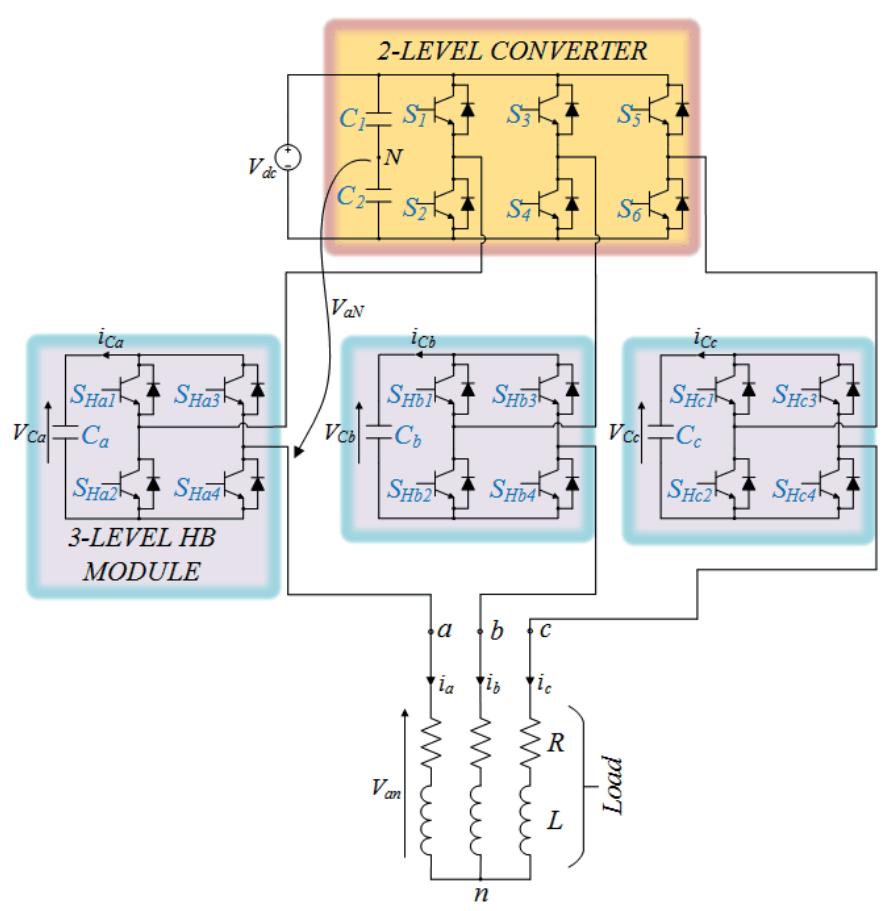

Fig. 1. Topology of five-level cascaded H-bridge converter (5LCHB)

If capacitors voltage $V_{C a}, V_{C b}, V_{C c}$ are kept by controller at voltage level $\frac{V_{D C}}{2}$ then converter generates five-level output waveform with voltage: $+V_{D C},+\frac{V_{D C}}{2}, 0,-\frac{V_{D C}}{2},-V_{D C}$ per phase when referenced to point $N$.

The switching pattern with the correspondent output voltage level for single phase $a$ is given in Table 1 .

Table 1

Switching pattern and corresponding output voltage level

\begin{tabular}{|c|c|c|c|c|c|c|}
\hline$S_{1}$ & $S_{2}$ & $S_{H a 1}$ & $S_{H a 2}$ & $S_{H a 3}$ & $S_{H a 4}$ & Output voltage $S_{a N}$ \\
\hline 1 & 0 & 0 & 1 & 1 & 0 & $+V_{D C}$ \\
\hline 1 & 0 & 1 & 0 & 1 & 0 & $+V_{D C} / 2$ \\
\hline 1 & 0 & 0 & 1 & 0 & 1 & 0 \\
\hline 1 & 0 & 1 & 0 & 0 & 1 & 0 \\
\hline 0 & 1 & 0 & 1 & 1 & 0 & $-V_{D C} / 2$ \\
\hline 0 & 1 & 1 & 0 & 1 & 0 & $-V_{D C}$ \\
\hline 0 & 1 & 0 & 1 & 0 & 1 & 1 \\
\hline 0 & 1 & 1 & 0 & 0 & 1 & \\
\hline
\end{tabular}

\section{Mathematical model}

The load current dynamics for RL load can be described as follows:

$$
\begin{gathered}
V_{x N}=R i_{x}+L \frac{d i_{x}}{d t}+V_{n N} \\
V_{x N}=S_{x} V_{D C}
\end{gathered}
$$

where $x=\{a, b, c\}$.

Voltage level indexes $S_{a}, S_{b}, S_{c}$, and individual level numbers $k_{a}, k_{b}, k_{c}$ for phases $a, b, c$ are defined in Tables 2-4.

Table 2

Converter output voltage level with corresponding voltage level index $S_{a}$ and individual level number $k_{a}$

\begin{tabular}{|c|c|c|c|c|c|c|c|c|}
\hline \multirow{2}{*}{$V_{a N}$} & \multirow{2}{*}{$S_{a}$} & \multirow{2}{*}{$k_{a}$} & \multicolumn{7}{|c|}{ Switches } \\
\cline { 5 - 10 } & & & $S_{1}$ & $S_{2}$ & $S_{H a 1}$ & $S_{H a 2}$ & $S_{H a 3}$ & $S_{H a 4}$ \\
\hline$+V_{D C}$ & 1 & 7 & 1 & 0 & 0 & 1 & 1 & 0 \\
\hline$+V_{D C} / 2$ & 0.5 & 6 & 1 & 0 & 1 & 0 & 1 & 0 \\
\hline$+V_{D C} / 2$ & 0.5 & 5 & 1 & 0 & 0 & 1 & 0 & 1 \\
\hline 0 & 0 & 4 & 1 & 0 & 1 & 0 & 0 & 1 \\
\hline 0 & 0 & 3 & 0 & 1 & 0 & 1 & 1 & 0 \\
\hline$-V_{D C} / 2$ & -0.5 & 2 & 0 & 1 & 1 & 0 & 1 & 0 \\
\hline$-V_{D C} / 2$ & -0.5 & 1 & 0 & 1 & 0 & 1 & 0 & 1 \\
\hline$-V_{D C}$ & -1 & 0 & 0 & 1 & 1 & 0 & 0 & 1 \\
\hline
\end{tabular}

Table 3

Converter output voltage level with corresponding voltage level index $S_{b}$ and individual level number $k_{b}$

\begin{tabular}{|c|c|c|c|c|c|c|c|c|}
\hline \multirow{2}{*}{$V_{b N}$} & \multirow{2}{*}{$S_{b}$} & \multirow{2}{*}{$k_{b}$} & \multicolumn{7}{|c|}{ Switches } \\
\cline { 5 - 10 } & & & $S_{3}$ & $S_{4}$ & $S_{H b 1}$ & $S_{H b 2}$ & $S_{H b 3}$ & $S_{H b 4}$ \\
\hline$+V_{D C}$ & 1 & 7 & 1 & 0 & 0 & 1 & 1 & 0 \\
\hline$+V_{D C} / 2$ & 0.5 & 6 & 1 & 0 & 1 & 0 & 1 & 0 \\
\hline$+V_{D C} / 2$ & 0.5 & 5 & 1 & 0 & 0 & 1 & 0 & 1 \\
\hline 0 & 0 & 4 & 1 & 0 & 1 & 0 & 0 & 1 \\
\hline 0 & 0 & 3 & 0 & 1 & 0 & 1 & 1 & 0 \\
\hline$-V_{D C} / 2$ & -0.5 & 2 & 0 & 1 & 1 & 0 & 1 & 0 \\
\hline$-V_{D C} / 2$ & -0.5 & 1 & 0 & 1 & 0 & 1 & 0 & 1 \\
\hline$-V_{D C}$ & -1 & 0 & 0 & 1 & 1 & 0 & 0 & 1 \\
\hline
\end{tabular}

Table 4

Converter output voltage level with corresponding voltage level index $S_{c}$ and individual level number $k_{c}$

\begin{tabular}{|c|c|c|c|c|c|c|c|c|}
\hline \multirow{2}{*}{$V_{c N}$} & \multirow{2}{*}{$S_{c}$} & \multirow{2}{*}{$k_{c}$} & \multicolumn{7}{|c|}{ Switches } \\
\cline { 5 - 9 } & & & $S_{5}$ & $S_{6}$ & $S_{H c 1}$ & $S_{H c 2}$ & $S_{H c 3}$ & $S_{H c 4}$ \\
\hline$+V_{D C}$ & 1 & 7 & 1 & 0 & 0 & 1 & 1 & 0 \\
\hline$+V_{D C} / 2$ & 0.5 & 6 & 1 & 0 & 1 & 0 & 1 & 0 \\
\hline$+V_{D C} / 2$ & 0.5 & 5 & 1 & 0 & 0 & 1 & 0 & 1 \\
\hline 0 & 0 & 4 & 1 & 0 & 1 & 0 & 0 & 1 \\
\hline 0 & 0 & 3 & 0 & 1 & 0 & 1 & 1 & 0 \\
\hline$-V_{D C} / 2$ & -0.5 & 2 & 0 & 1 & 1 & 0 & 1 & 0 \\
\hline$-V_{D C} / 2$ & -0.5 & 1 & 0 & 1 & 0 & 1 & 0 & 1 \\
\hline$-V_{D C}$ & -1 & 0 & 0 & 1 & 1 & 0 & 0 & 1 \\
\hline
\end{tabular}


Capacitor currents can be defined as:

$$
i_{c x}=H_{x} i_{x}
$$

where $H_{x}$ can be defined as follows:

$$
H_{x}=\left\{\begin{aligned}
& 1 \text { for } k_{x}=0 \text { or } 4 \\
& 0 \text { for } k_{x}=1 \text { or } 2 \text { or } 5 \text { or } 6 \\
&-1 \text { for } k_{x}=3 \text { or } 7
\end{aligned}\right.
$$

with $x=\{a, b, c\}$.

There are $8^{3}=512$ valid switching states. This rises a crucial problem for practical implementation of predictive controller. In order to choose the optimal state, all combinations need to be evaluated in the cost function. In this case, the execution time will exceed the sampling period, which typically reaches values of $10-200 \mu s$. Therefore, in this work phase voltage is taken as control input. Thus there is $5^{3}=125$ different space voltage vectors. This is still a large number of mathematical operations that need to be performed within one sampling period. In order to reduce number of mathematical operations, further simplification of the mathematical model was performed. In this work it is assumed that common voltage $v_{n N}$ is small and can be neglected in equation (1), then each phase can be considered separately and there are $3 \times 5=15$ voltage levels that need to be taken into account. The correctness of this assumption will be validated in experimental setup.

\section{Predictive current control}

Model predictive control (MPC) has appeared as a promising alternative to classical control algorithms with pulse width modulation (PWM) for power converters control $[18,19]$.

Predictive control can be divided into: deadbeat control, hysteresis based, trajectory based, model predictive control (MPC) [19]. Deadbeat control chooses optimal actuation that makes error equal to zero in the next sampling instant. Hysteresis based strategy is to keep the controlled variable within a boundaries of a hysteresis area. Trajectory based controller forces the variable to follow a predefined trajectory. This work utilizes finite-control-set model predictive current control (FCS-MPC). This strategy uses a discrete model of a converter and load to predict the behavior of the system for each possible voltage level generated by the converter for the predefined prediction horizon. The voltage level that minimizes a cost function is selected and applied during a whole sampling interval [20]. The application discussed in this paper have a horizon length of 1 .

The current of a sample $k+1$ for the model of the RL load from Fig. 1 with a sample time $T_{s}$ can be expressed as [21]:

$$
i_{x}^{p}(k+1)=\left(1-\frac{R T_{s}}{L}\right) i_{x}(k)+\frac{T_{s}}{L} v_{x N}(k)
$$

Predicted capacitor voltage can be expressed as:

$$
v_{C x}^{p}(k+1)=v_{C x}(k)+\frac{1}{C_{x}} i_{c x}(k) T_{s}
$$

where $x=\{a, b, c\}$.
To determine which output voltage level is an optimal one, the cost function needs to be evaluated. The proposed cost function $g$ is a sum of squared current and capacitors voltage errors:

$$
g=\frac{1}{I_{N}}\left(i_{x r e f}-i_{x}^{p}\right)^{2}+\frac{\lambda}{V_{C r e f}}\left(V_{\text {Cref }}-V_{C x}^{p}\right)^{2}
$$

where: $I_{N}$ - nominal current, $i_{x r e f}-$ reference current, $i_{x}^{p}-$ the predicted current from (11), $V_{C r e f}$ - reference voltage of capacitor $V_{C x}^{p}$ - predicted voltage of capacitors, $x=\{a, b, c\}$, $\lambda$ - weighting factor that determines relation between terms dedicated to current tracking and capacitors voltage balancing. The squared error formula used in (7) gives better reference tracking than the use of absolute error [22].

The evaluation of the cost function is made for all 5 possible output voltage levels per phase. The voltage level that leads to a minimum cost is selected to control the system. Capacitors voltage errors in a cost function provide capacitor voltage regulation. The whole algorithm of MPC is illustrated in Fig. 2.

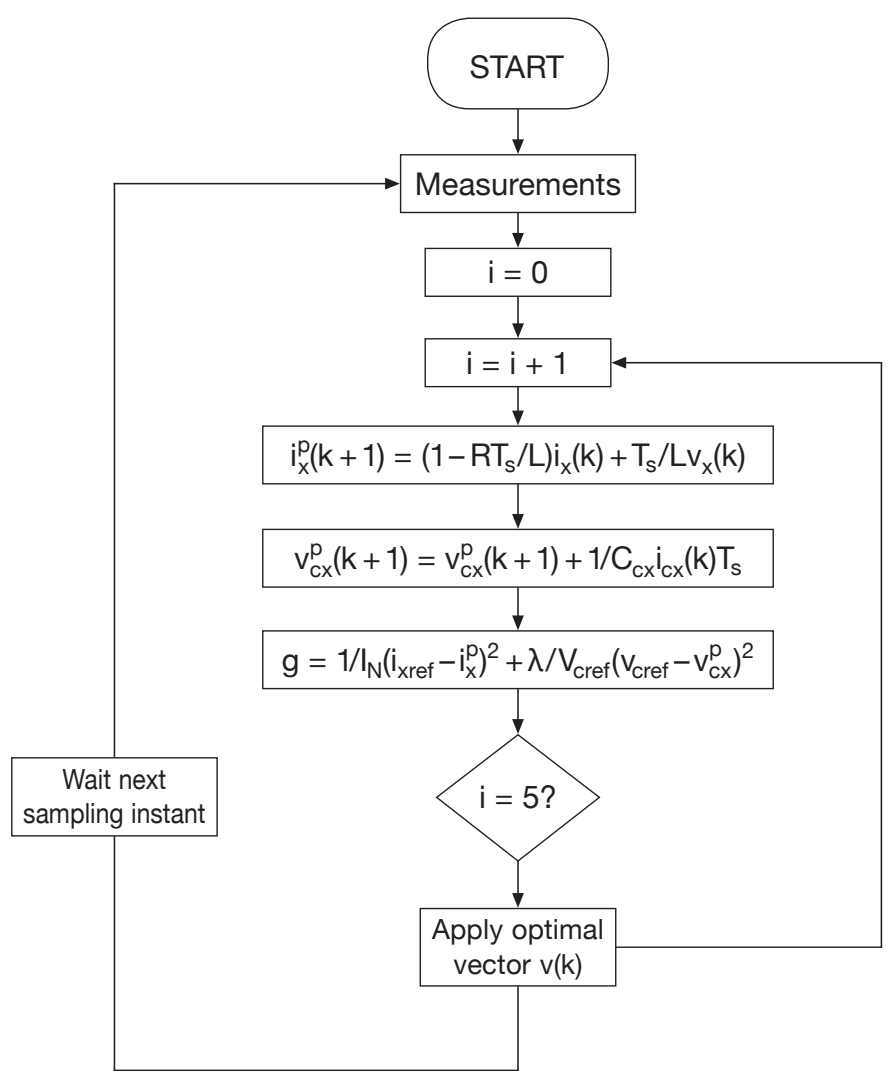

Fig. 2. MPC control algorithm

\section{Experimental prototype}

The $5 \mathrm{kVA}$ laboratory model was developed to present converter operation in the system analyzed in previous sections. The three phase two-level converter is supplied by fixed voltage source $V_{D C}$ split by two capacitors giving reference point $N$. Threelevel H-bridges are connected in series to each of three-leg two- 
P. Wiatr andA' Kryński

level converter. DC side of the H-bridge modules is powered by electrolytic capacitors. The 5LCHB inverter is connected to symmetric load consisting of variable resistor and inductance that allowed to test converters features at different load displacement angles $\varphi$.

Figure 3 shows schematic of experimental setup of threephase five-level cascaded H-bridge converter (5LCHB) powering RL load.

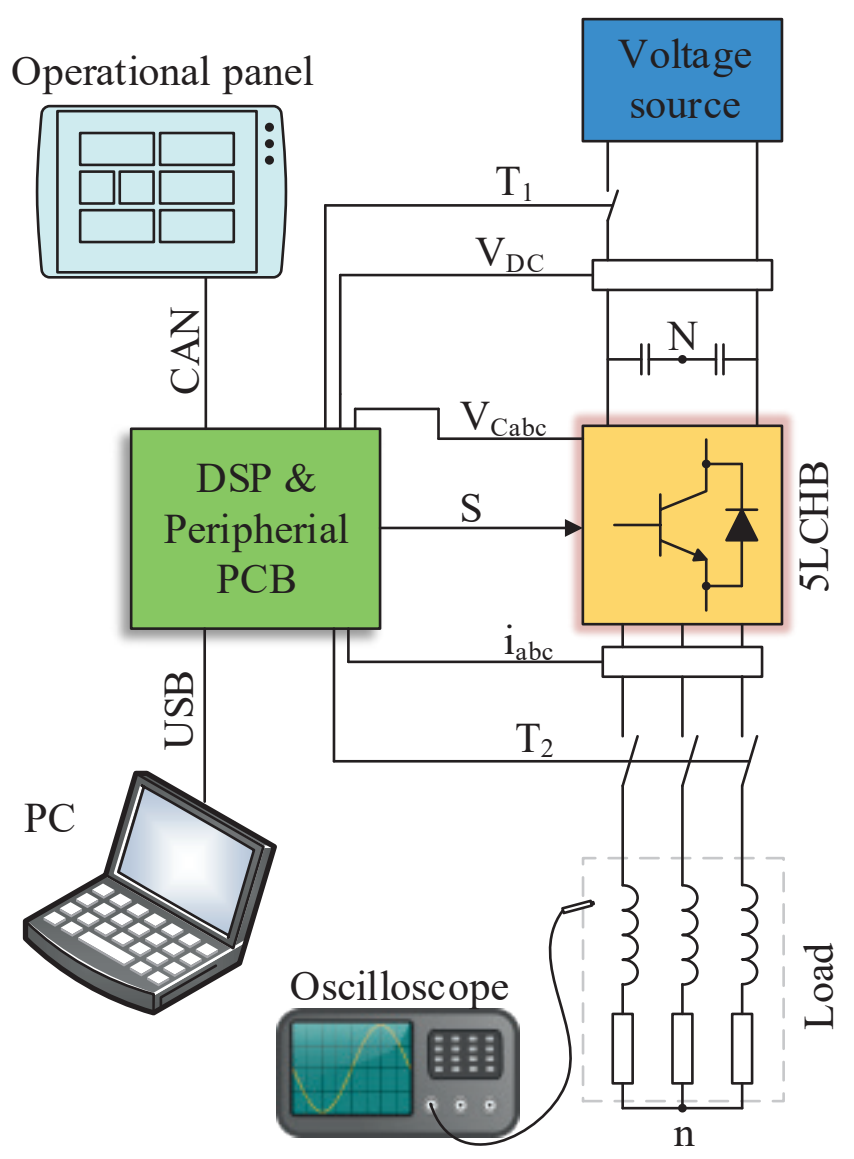

Fig. 3. Laboratory model schematic of 5LCHB converter with RL load

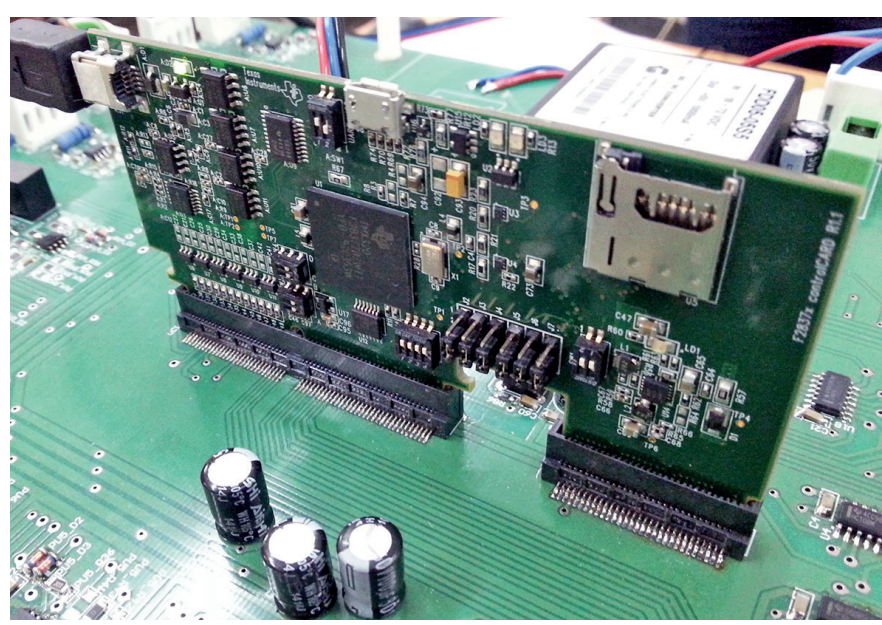

Fig. 4. Texas Instruments ControlCARD TMDSDOCK28377D

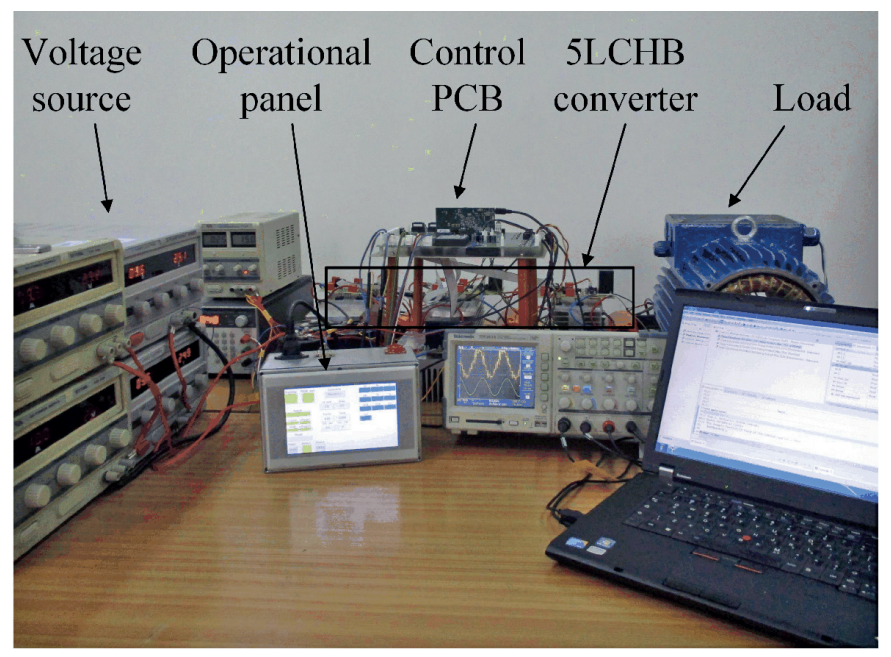

Fig. 5. View of the laboratory setup

The MPC algorithm with necessary calculations and controls have been implemented in Texas Instruments controlCARD with TMS320F28377D dual-core digital signal processor connected to peripheral board (Fig. 4).

The sampling frequency is set to $10 \mathrm{kHz}$ for correct inverter operation. To maintain load current regulation and capacitor voltage balance, LEM LA-55p transducers and AMC1100 isolation amplifiers are used.

Eaton's operational panel with touch screen used to interface with operator is responsible for entire system control and ensures preview of main signals and setting reference values for control algorithm. It is connected with DSP via CAN bus.

\section{Experimental results}

6.1. Basic characteristics. An experimental test of the 5LCHB converter with model predictive controller for RL type of load was carried out. System parameters are shown in Table 5.

Table 5

System parameters

\begin{tabular}{|c|c|l|}
\hline $\begin{array}{c}\text { System } \\
\text { parameters }\end{array}$ & Value & \multicolumn{1}{c|}{ Description } \\
\hline$V_{D C}$ & $100 \mathrm{~V}$ & DC power supply voltage \\
\hline$V_{C r e f}$ & $50 \mathrm{~V}$ & Capacitors reference voltage \\
\hline \multirow{2}{*}{$C$} & $6800 \mu F$ & $\begin{array}{l}\text { Capacitance of capacitors } \\
C_{a}, C_{b}, C_{c}\end{array}$ \\
\hline \multirow{2}{*}{$R$} & $\begin{array}{c}\text { Depend } \\
\text { on a phase } \\
\text { displacement } \\
\text { angle } \varphi\end{array}$ & Load resistance \\
\cline { 1 - 3 } & $\begin{array}{c}100 \mu s \\
T_{s}\end{array}$ & Load inductance \\
\cline { 1 - 2 }$f$ & $50 \mathrm{~Hz}$ & Reference current frequency \\
\hline
\end{tabular}


For measurements the Yokogawa WT1806 Precision Power Analyzer and Tektronix TPS2014 oscilloscope were used.

The modulation index definition used for the experiment is written as:

$$
m=\frac{V_{1}}{V_{D C} / 2}
$$

where $V_{1}$ is the fundamental harmonic of the output phase voltage. Phase voltages, phase currents, capacitor voltages and currents for different modulation indexes and different phase displacement angles are depicted in Figs. 6-19.

The maximum modulation index for the tested converter for different phase displacement angles and corresponding

a) Results for phase displacement angle $\varphi=58^{\circ}$

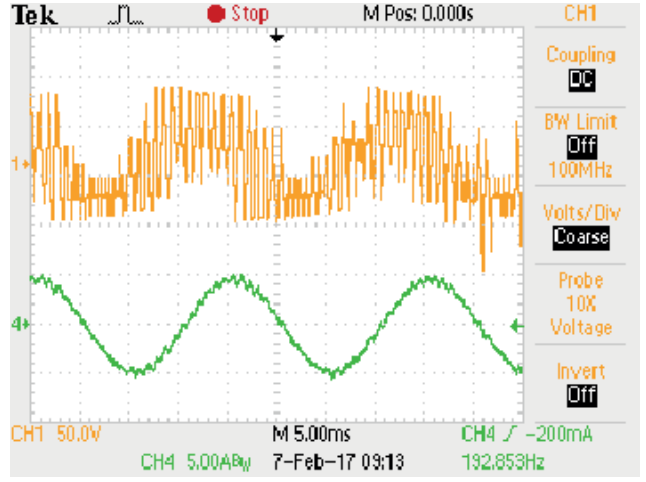

Fig. 6. Phase voltage $V_{a n}$ (top), phase current $i_{a}$ (bottom) for $R=2.9 \Omega, L=14.9 \mathrm{mH}, m=0.5, \varphi=58^{\circ}$

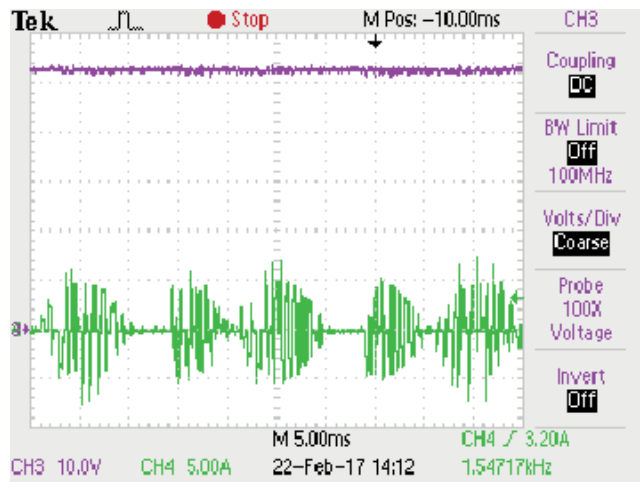

Fig. 7. Voltage (top) and current (bottom) of capacitor $C_{a}$ for $R=2.9 \Omega, L=14.9 \mathrm{mH}, m=0.5, \varphi=58^{\circ}$

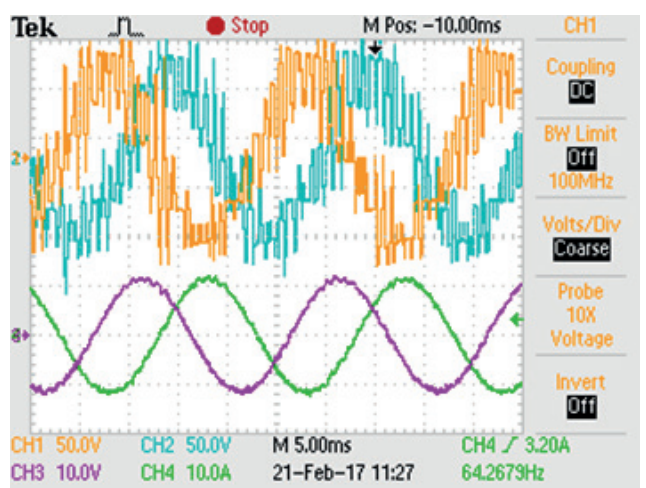

Fig. 8. Phase voltages $V_{a n}, V_{b n}$ (top), phase current $i_{a}, i_{b}$ (bottom) for $R=2.9 \Omega, L=14.9 \mathrm{mH}, m=1.2, \varphi=58^{\circ}$

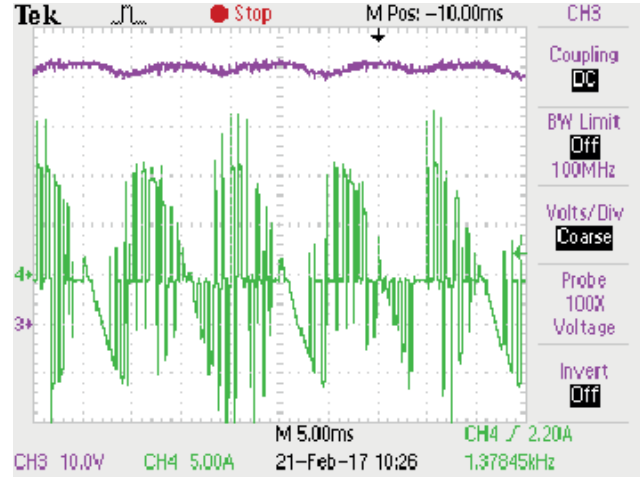

Fig. 9. Voltage (top) and current (bottom) of capacitor $C_{a}$ for $R=2.9 \Omega, L=14.9 \mathrm{mH}, m=1.2, \varphi=58^{\circ}$

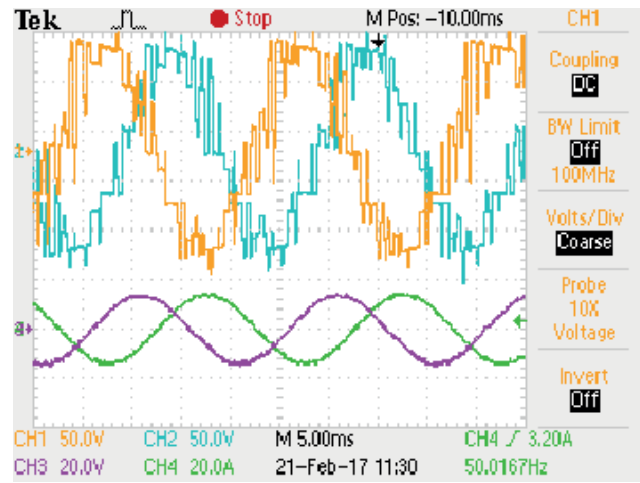

Fig. 10. Phase voltages $V_{a n}, V_{b n}$ (top), phase current $i_{a}, i_{b}$ (bottom) $R=2.9 \Omega, L=14.9 \mathrm{mH}, m=1.55, \varphi=58^{\circ}$

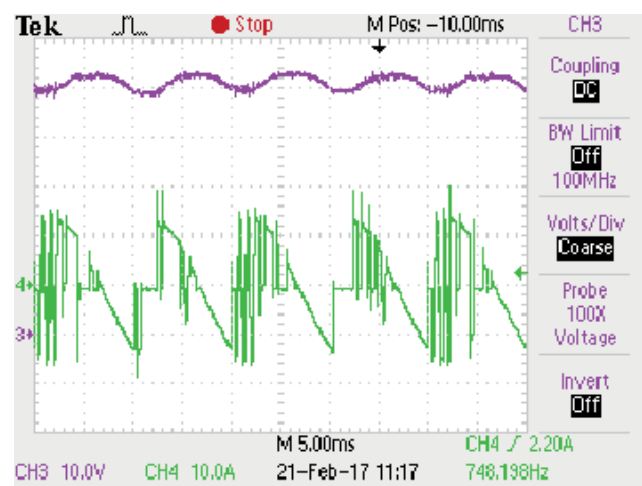

Fig. 11. Voltage (top) and current (bottom) of capacitor $C_{a}$ for $R=2.9 \Omega, L=14.9 \mathrm{mH}, m=1.55, \varphi=58^{\circ}$ 
P. Wiatr and"A. Kryński

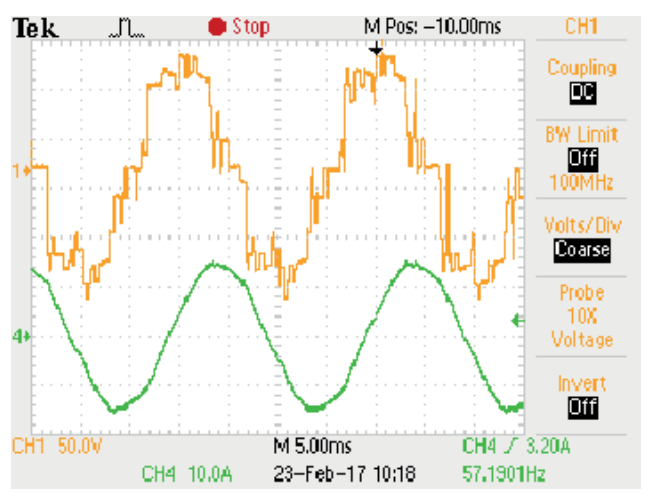

Fig. 12. Phase voltage $V_{a n}$ (top), phase current $i_{a}$ (bottom) for $R=2.9 \Omega, L=14.9 \mathrm{mH}, m=1.8, \varphi=58^{\circ}$

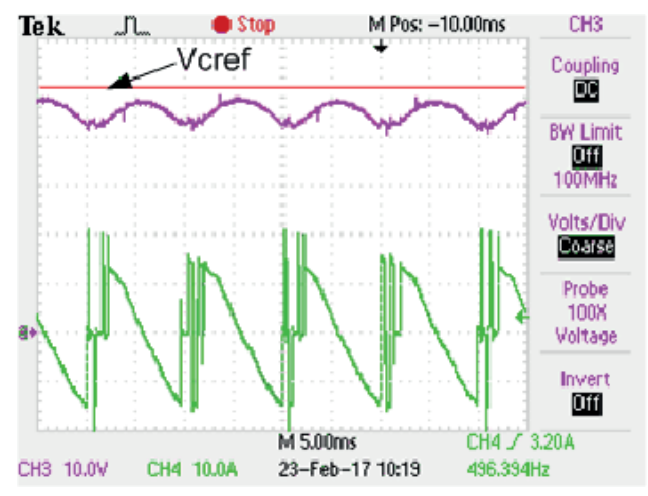

Fig. 13. Voltage (top) and current (bottom) of capacitor $C_{a}$ for $R=2.9 \Omega, L=14.9 \mathrm{mH}, m=1.8, \varphi=58^{\circ}$

b) Results for phase displacement angle $\varphi=28^{\circ}$

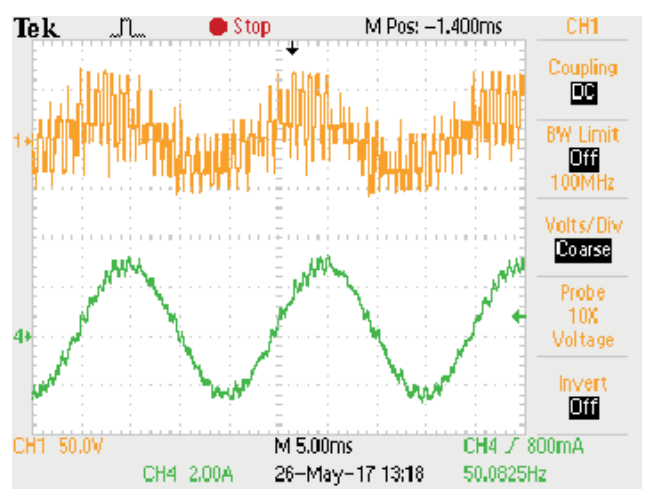

Fig. 14. Phase voltage $V_{a n}$ (top), phase current $i_{a}$ (bottom) for $R=8.7 \Omega, L=14.9 \mathrm{mH}, m=0.5, \varphi=28^{\circ}$

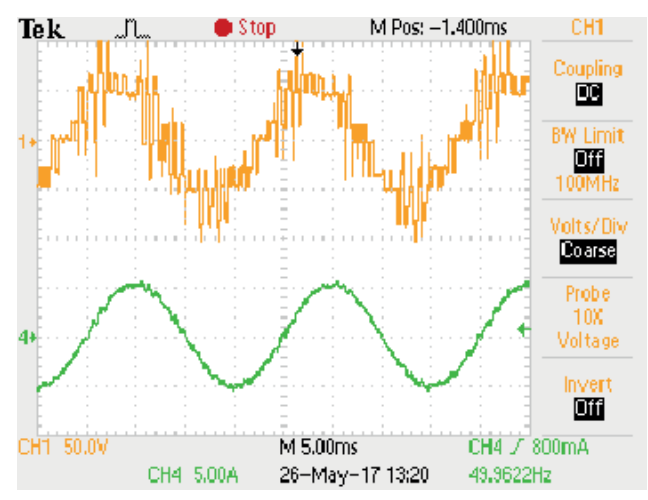

Fig. 15. Phase voltage $V_{a n}$ (top), phase current $i_{a}$ (bottom) for $R=8.7 \Omega, L=14.9 \mathrm{mH}, m=1, \varphi=28^{\circ}$

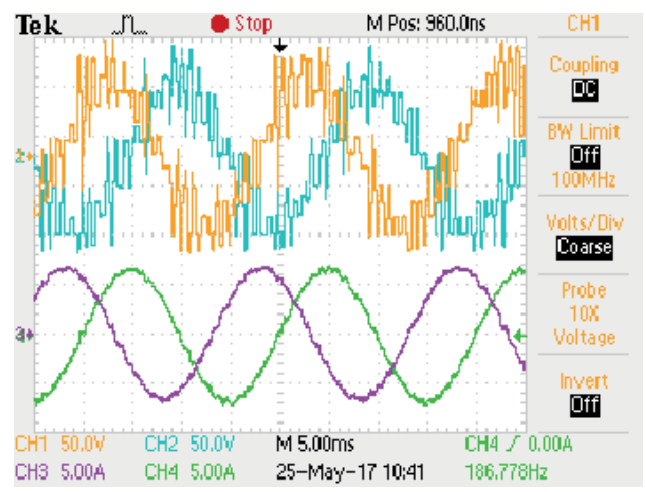

Fig. 16. Phase voltages $V_{a n}, V_{b n}$ (top), phase current $i_{a}, i_{b}$ (bottom) for $R=8.7 \Omega, L=14.9 \mathrm{mH}, m=1.3, \varphi=28^{\circ}$ 
c) Results for phase displacement angle $\varphi=76^{\circ}$

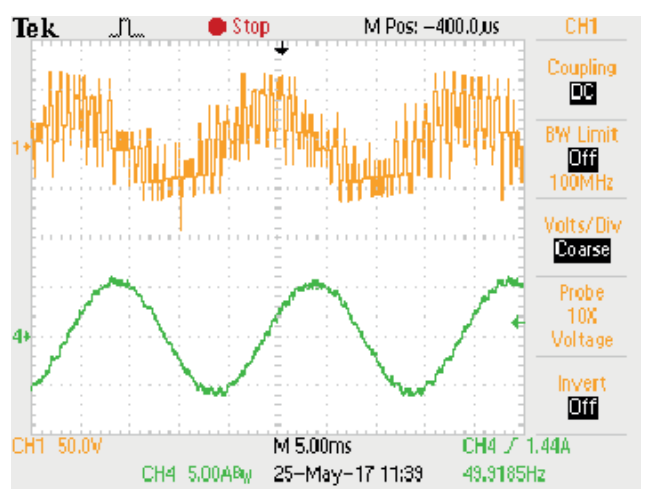

Fig. 17. Phase voltage $V_{a n}$ (top), phase current $i_{a}$ (bottom) for $R=1.16 \Omega, L=14.9 \mathrm{mH}, m=0.5, \varphi=76^{\circ}$

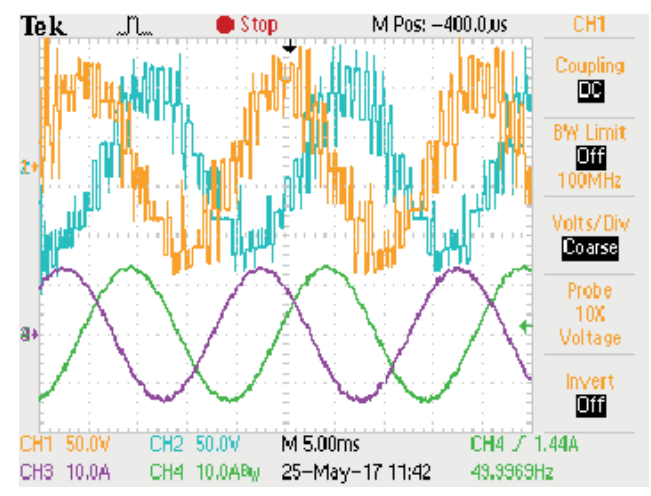

Fig. 18. Phase voltages $V_{a n}, V_{b n}$ (top), phase current $i_{a}, i_{b}$ (bottom) for $R=1.16 \Omega, L=14.9 \mathrm{mH}, m=1.2, \varphi=76^{\circ}$

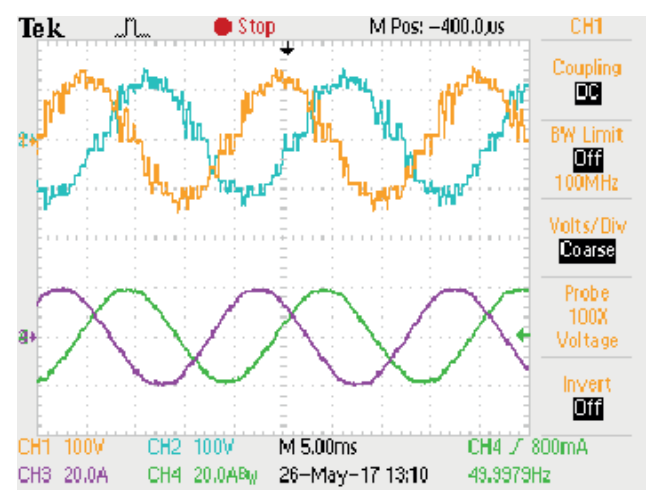

Fig. 19. Phase voltages $V_{a n}, V_{b n}$ (top), phase current $i_{a}, i_{b}$ (bottom) for $R=1.16 \Omega, L=14.9 \mathrm{mH}, m=1.8, \varphi=76^{\circ}$

d) Dynamic behavior for $\varphi=58^{\circ}$

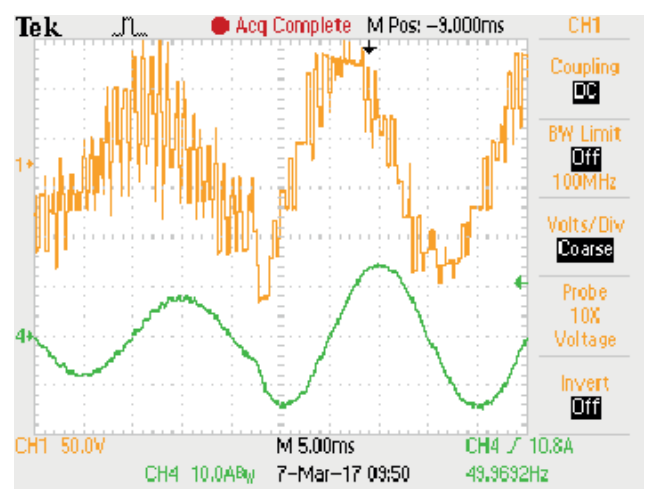

Fig. 20. Voltage (top), current $i_{a}$ (bottom) for current reference step which corresponds to modulation index from $m=0.8$ to $m=1.55$ for $R=2.9 \Omega, L=14.9 \mathrm{mH}, m=0.5, \varphi=58^{\circ}$

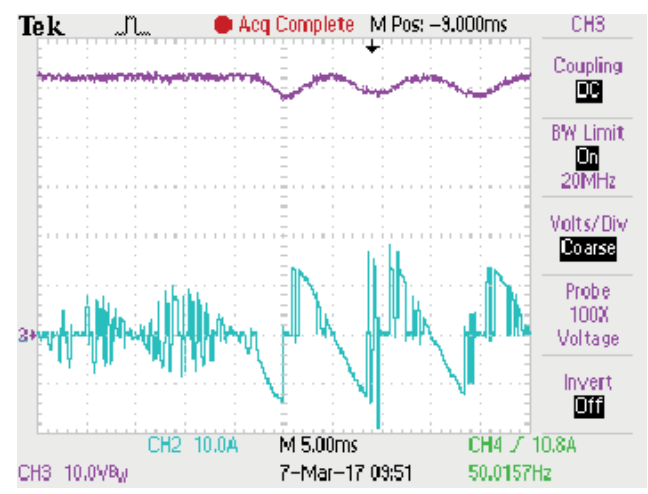

Fig. 21. Voltage (top) and current (bottom) of capacitor $C_{a}$ for current reference step which corresponds to modulation index from $m=0.8$ to $m=1.55$ for $R=2.9 \Omega, L=14.9 \mathrm{mH}, \varphi=58^{\circ}$ 
boosting ratio is shown in Table 6 . Boosting ratio is defined as follows:

$$
\text { boosting ratio }=\frac{I_{m a x \_5 l}}{I_{\max \_2 l}}
$$

where: $I_{\text {max } \_5 l}-$ maximum current for a given load for $5 \mathrm{LCHB}$ converter, $I_{\text {max } \_l}-$ maximum current for a given load for classical two-level converter.

Table 6

\begin{tabular}{|c|c|c|}
\hline $\begin{array}{c}\text { Maximum } \\
\text { modulation index m }\end{array}$ & Boosting ratio & $\begin{array}{c}\text { Phase displacement } \\
\text { angle } \varphi\end{array}$ \\
\hline 1.3 & 1.13 & $28^{\circ}$ \\
\hline 1.55 & 1.34 & $58^{\circ}$ \\
\hline 1.8 & 1.56 & $76^{\circ}$ \\
\hline
\end{tabular}

Maximum current for the 5LCHB converter is presented in Table 7.

Table 7

\begin{tabular}{|c|c|c|}
\hline $\begin{array}{c}\text { Maximum current } \\
\text { for classical 3-phase } \\
\text { two-level converter }\end{array}$ & $\begin{array}{c}\text { Maximum current } \\
\text { for 5LCHB } \\
\text { converter }\end{array}$ & $\begin{array}{c}\text { Phase } \\
\text { displacement } \\
\text { angle } \varphi\end{array}$ \\
\hline $5.83 \mathrm{~A}$ & $6.57 \mathrm{~A}$ & $28^{\circ}$ \\
\hline $10.48 \mathrm{~A}$ & $14 \mathrm{~A}$ & $58^{\circ}$ \\
\hline $11.97 \mathrm{~A}$ & $18.66 \mathrm{~A}$ & $76^{\circ}$ \\
\hline
\end{tabular}

When modulation index exceeds the maximum from Table 6 converter goes beyond the linear region of operation. With the increasing of modulation index, capacitors voltage ripples also increases (Table 8). It is caused by the rise of the capacitor current. When modulation index is too high, phase current becomes distorted (Fig. 12) and the controller loses its capability to balance capacitor's voltage, which drops below the reference level (Fig. 13). In order to test the dynamic behavior of the system, the phase current step was performed (Fig. 20 and Fig. 21). It can be noticed that during the new reference current step the selected optimal voltage vector is kept as long as the load current achieves the reference value. Capacitors voltage ripple increases after current change but remains stable. That confirms an effective operation of capacitors voltage balancing.

Table 8

Capacitor voltage ripple

\begin{tabular}{|c|c|}
\hline $\begin{array}{c}\text { Capacitor voltage ripple } \\
{[\mathrm{V}]}\end{array}$ & $\begin{array}{c}\text { Modulation } \\
\text { Index m }\end{array}$ \\
\hline 2.1 & 0.8 \\
\hline 3 & 1 \\
\hline 4 & 1.2 \\
\hline 5.12 & 1.5 \\
\hline 6.12 & 1.8 \\
\hline
\end{tabular}

Figures 6-15 confirm proper current control and capacitors voltage balancing capability by the model predictive controller

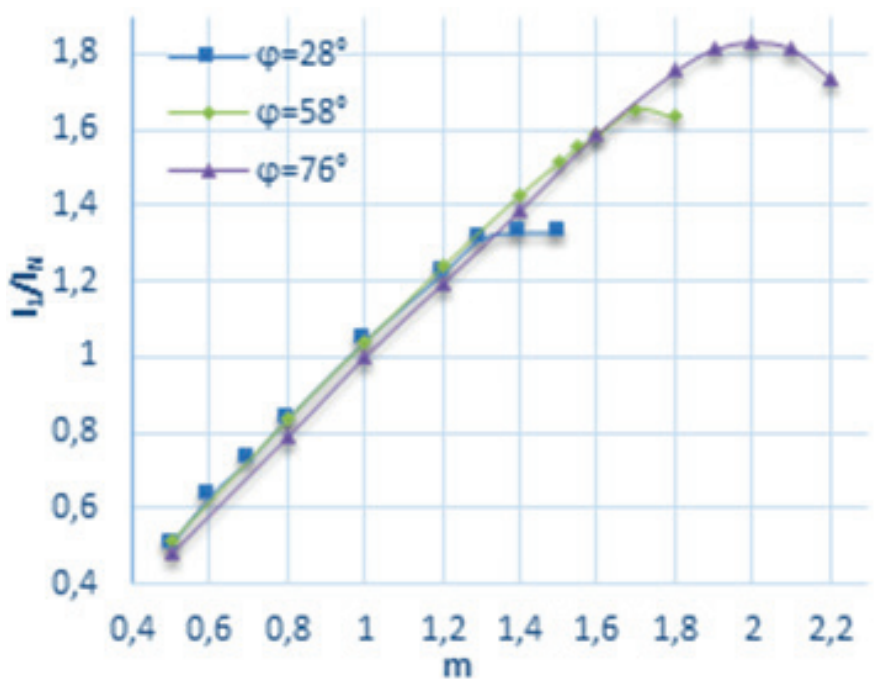

Fig. 22. Control characteristic of 5LCHB converter for different phase displacement angles $\varphi$

when common mode voltage is excluded from (1). Measuring fundamental harmonic mode of phase current for different modulation index, the control characteristic was designated (Fig. 22). Current $I_{N}$ is the maximum phase current available in linear region of operation of the two-level converter with PWM for the given RL load.

The bigger the phase displacement angle $\varphi$ is, the greater the linear part of control characteristic. That confirms theoretical considerations presented in [1].

6.2. Influence of weighting factor selection. The influence of weighting factor $\lambda$ on control characteristic for angle $\varphi=58^{\circ}$ was measured and depicted in Fig. 23.

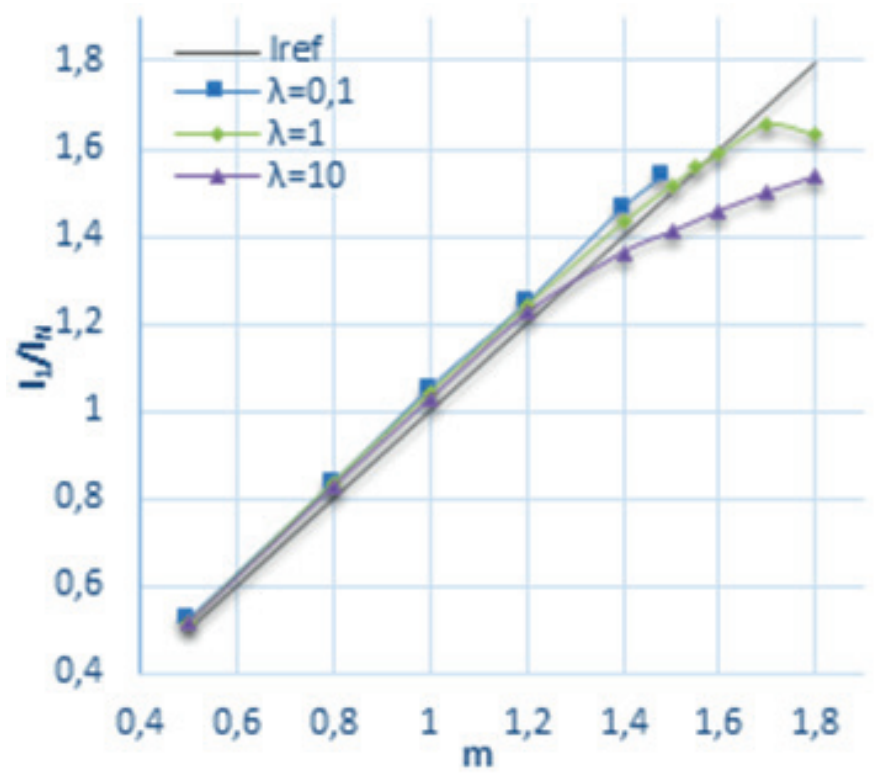

Fig. 23. Control characteristic of 5LCHB converter for different weighting factor values $\lambda$ for $R=2.9 \Omega, L=14.9 \mathrm{mH}, \varphi=58^{\circ}$ 
Current $I_{r e f}$ depics the ideal characteristic. The control characteristic for $\lambda=0.1$ loses ability to balance capacitors voltage for modulation index higher than $m=1.4$. It can be noticed that in the linear region there is a steady state error between the ideal characteristic of $I_{r e f}$ and the measured characteristics. It is caused by the lack of an integration action in predictive controller.

The quality of output waveforms was measured using $T H D_{u}$, $T H D_{i}$ and mean absolute tracking error, which is defined as the mean value the absolute differences between the reference current and measured load current, within a given time interval of $l$ samples:

$$
e_{i}=\frac{1}{l} \sum_{k=0}^{l}|\operatorname{iref}(k)-i(k)|
$$

Figure 24 shows the current error $e_{i}$ versus modulation index for different weighting factor $\lambda$.

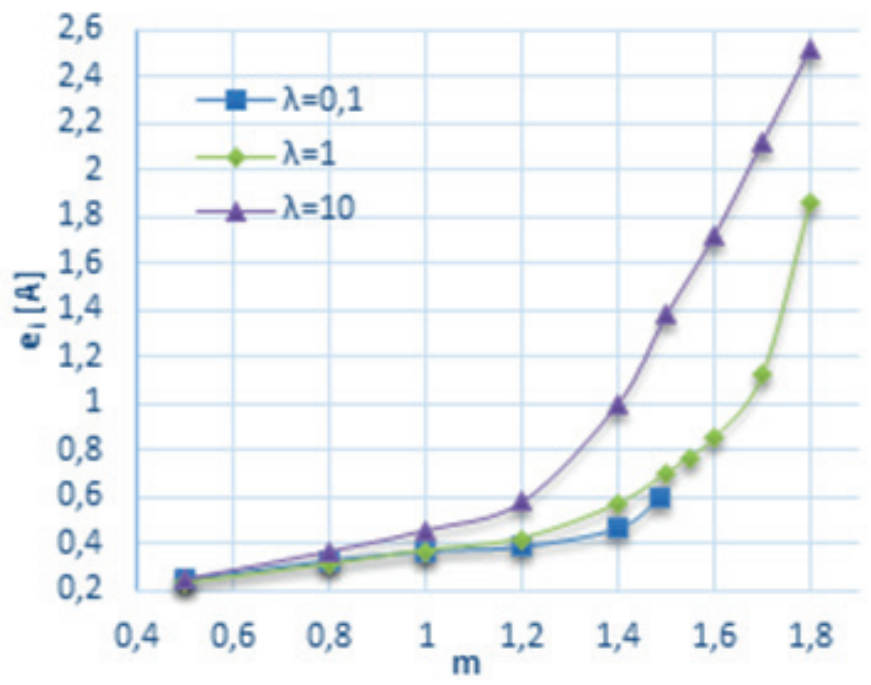

Fig. 24. Mean value of tracking error for $\lambda=0.1, \lambda=1$ and $\lambda=10$ and $R=2.9 \Omega, L=14.9 \mathrm{mH}, \varphi=58^{\circ}$

It can be seen that the smallest error in a wide range of modulation index changes is for $\lambda=0.1$. When parameter $\lambda$ is small, the capacitor voltage error has small impact on a cost function value and better current tracking is achieved. The drawback of low value of $\lambda$ is lower maximum available modulation index. When the value of $\lambda$ is high, the modulation index range is wide at the expense of higher current error $e_{i}$.

Figure 25 and Fig. 26 show a $T H D_{u}$ and $T H D_{i}$ versus modulation index m. The $T H D_{u}$ diagram can be divided into three regions. First region corresponds to the linear part of control characteristic from Fig. 23. For low modulation index, $T H D_{u}$ is high, because output voltage is not constructed with all possible voltage levels. When modulation index increases, additional levels are added to the waveform and the output voltage be- comes a sinusoidal shape, so $T H D_{u}$ is getting lower. The second region corresponds to the nonlinear part of control characteristic. In this part capacitors voltage error greatly increases and capacitor voltage balancing is performed at the expense of current quality. That causes a sudden rise of $T H D_{u}$. In the third region, output phase voltage saturates and the level flattens. The $T H D_{u}$ diagram for $\lambda=0.1$ is located completely in region I. For modulation index $m$ greater than $m=1.48$ system loses ability to balance capacitors voltage.

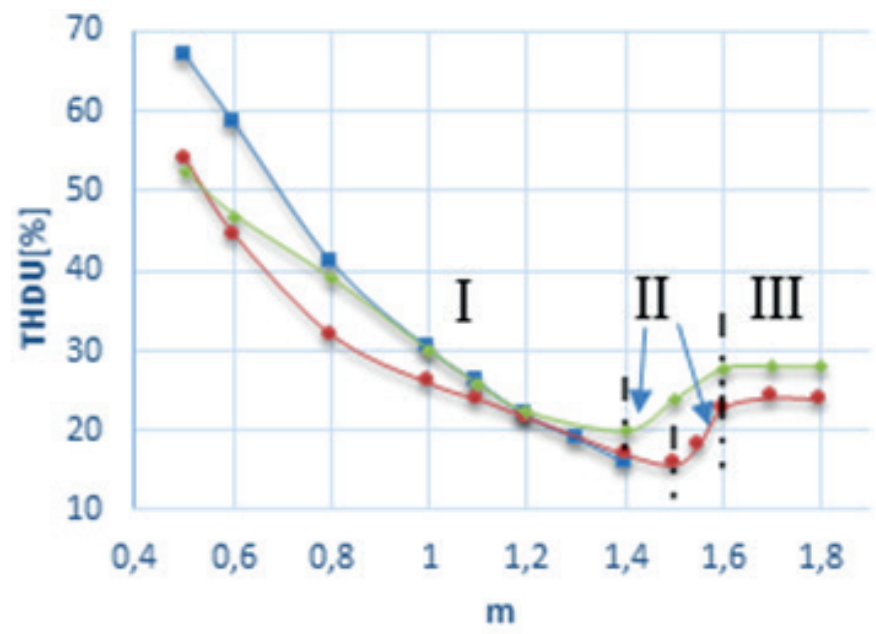

Fig. 25. $T H D_{u}$ of phase voltage for $\lambda=1$ and $R=2.9 \Omega, L=14.9 \mathrm{mH}$, $\varphi=58^{\circ}$

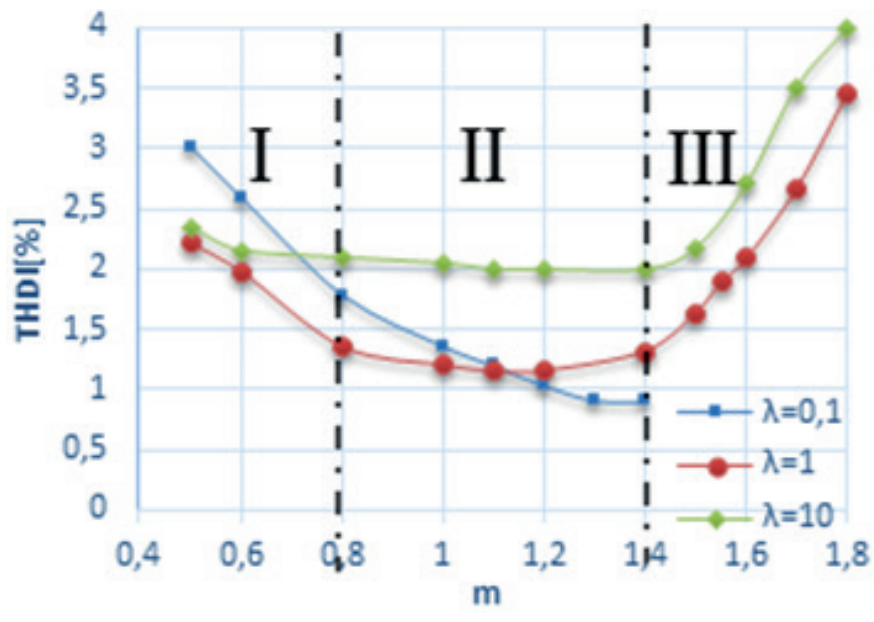

Fig. 26. $T H D_{i}$ of phase current for $\lambda=1$ for $R=2.9 \Omega, L=14.9 \mathrm{mH}$, $\varphi=58^{\circ}$

The $T H D_{i}$ diagram can be divided into three regions as well. An example division was made for $\lambda=1$. It can be seen that in the first region the $T H D_{i}$ gets lower with the modulation index increase. It is caused by the increase in number of levels in phase voltage. In the second region the $T H D_{i}$ reaches plateau. In the third region, due to voltage balancing, the phase voltage gets distorted, causing $T H D_{i}$ to increase. 
6.3. Influence of model parameter errors. The impact of mathematical model parameters error was also examined. Applying different value of resistance than the actual value of the load resistance, the error $e_{i}$ was measured. Figure 27 and Fig. 28 presents error $e_{i}$ for different values of resistance $R$ applied to load model (5).

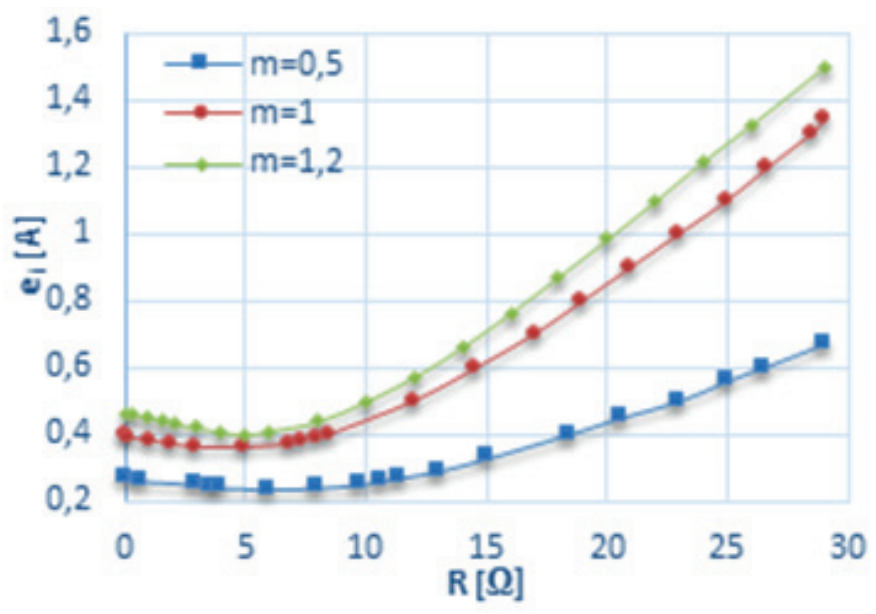

Fig. 27. Mean value of tracking error versus $\mathrm{R}$ for load resistance $5 \Omega$ and inductance $14.9 \mathrm{mH}$ and $\lambda=1$

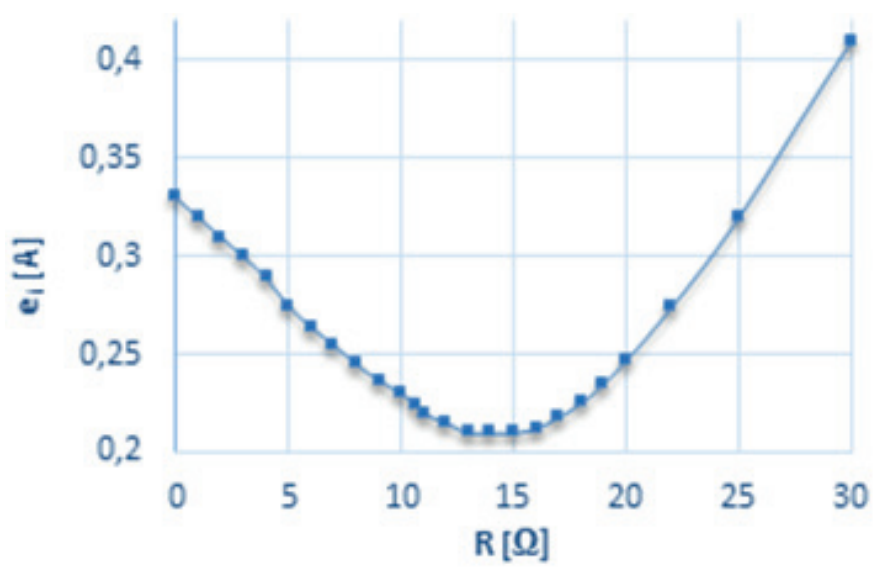

Fig. 28. Mean value of tracking error versus $\mathrm{R}$ change for load resistance $14 \Omega$ and inductance $14.9 \mathrm{mH}$ and $\lambda=1$

The error $e_{i}$ reaches minimum around the actual value of the load $R=5 \Omega$. The function of $e_{i}$ versus load resistance $\mathrm{R}$ is symmetrical to the point of actual resistance. It can be seen that this function flattens around its minimum. That means that small error of load model resistance has small impact on the performance of the system.

Applying different value of inductance to the load model error $e_{i}$ was measured and depicted in Fig. 29. It can be noticed that the function reaches its minimum around the point of the actual value of inductance. For smaller inductance than the actual one, the error $e_{i}$ drastically rises. When bigger value

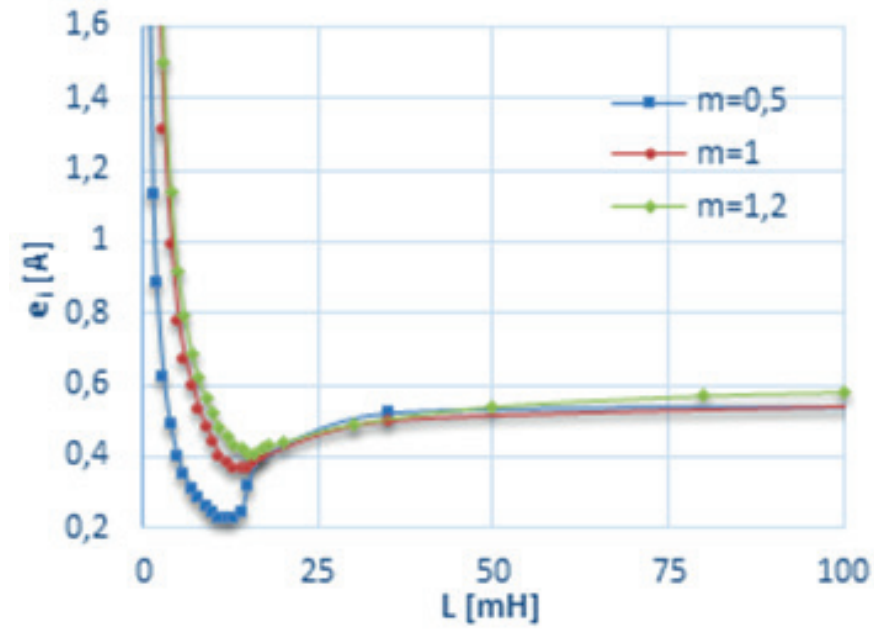

Fig. 29. Mean value of tracking error versus model $\mathrm{L}$ change for load resistance $14 \Omega$ and inductance $14.9 \mathrm{mH}$ and $\lambda=1$

of inductance is applied, the error slightly increases but then function flattens. That means it is safer to apply bigger value of inductance when parameters of the load are not precisely known.

\section{Conclusions}

The paper analyzes cascaded H-bridge five-level converter with model predictive control (MPC). The proposed predictive algorithm performs output current control and capacitor voltage balancing. A simplification of mathematical model of the load with omitting the common-mode voltage $V_{n N}$ made it possible to implement proposed MPC algorithm in Texas Instruments controlCARD with TMS320F28377D processor. The algorithm execution time was $16 \mu s$ with $100 \mu s$ sampling period. Experiments confirm proper current control and capacitors voltage balancing by the system. The examined 5LCHB converter with MPC control can boost output ac voltage with maximum modulation index $m=1.8$ for phase displacement angle $\varphi=76^{\circ}$. The control characteristic of 5LCHB converter for different phase displacement angle $\varphi$ and weighting parameter $\lambda$ was presented. The quality of output phase current was measured using $T H D_{u}$, $T H D_{i}$ and mean absolute tracking error $e_{i}$. Utilizing the error $e_{i}(10)$, the sensitivity to mathematical parameters error was examined.

Acknowledgments. This work was supported by the National Science Centre as the scientific project number DEC2014/15/N/ST7/05067.

\section{REFERENCES}

[1] P. Wiatr and M. Kaźmierkowski, "Model predictive control of five-level cascaded H-bridge converter - simulation study", Bull. Pol. Ac.: Tech 64 (3), 581-590 (2016) 
[2] ABB. [online]: www.abb.com

[3] Alstom. [online]: www.alstom.com

[4] TMEIC. [online]: www.tmeic.com

[5] Eaton. [online]: www.eaton.com

[6] S. Kouro, M. Malinowski, K. Gopakumar, J. Pou, L.G. Franquelo, B. Wu, J. Rodriguez, M.A. Pérez, and J. I. Leon, "Recent advances and industrial applications of multilevel converters", IEEE Trans. Ind. Electron. 57 (8), 2553-2580 (2010).

[7] M. Zygmanowski, B. Grzesik, and J. Michalak, "Properties of the power conditioning system with a five-level cascaded converter and supercapacitor energy storage", Bull. Pol. Ac.: Tech. 59 (4), 525-534 (2011).

[8] M.A. Perez, S. Bernet, J. Rodriguez, S. Kouro, and R. Lizana, "Circuit topologies, modeling, control schemes, and applications of modular multilevel converters", IEEE Transactions on Power Electronics 30 (1), 4-17, (2015).

[9] H. Akagi, "Classification, terminology, and application of the modular multilevel cascade converter (MMCC)", IEEE Transactions on Power Electronics 26 (11), 3119-3130, (2011).

[10] A. Nami, J. Liang, F. Dijkhuizen, and G.D. Demetriades, "Modular multilevel converters for HVDC applications: Review on converter cells and functionalities," IEEE Transactions on Power Electronics 30 (1), 18-36 (2015).

[11] Z. Cheng and $\mathrm{B}$. Wu, "A novel switching sequence design for five-level NPC/H-bridge inverters with improved output voltage spectrum and minimized device switching frequency," in IEEE Transactions on Power Electronics, 22 (6), 2138-2145 (2007).

[12] A.F. Kieferndorf, M. Basler, L.A. Serpa, J.-H. Fabian, A. Coccia, and G. A. Scheuer, "A new medium voltage drive system based on ANPC-5L technology," Proc. IEEE ICIT, 605-611 (2010).

[13] C. Silva, P. Kouro, J. Soto, and P. Lezana, "Control of an hybrid multilevel inverter for current waveform improvement," Proc. IEEE ISIE, 2329-2335 (2008).
[14] P. Rodriguez, M.D. Bellar, R.S. Muñoz-Aguilar, S. BusquetsMonge, and F. Blaabjerg, "Multilevel-clamped multilevel converters (MLC)", IEEE Transactions on Power Electronics 27 (3), 1055-1060, (2012).

[15] P. Wiatr and M.P. Kaźmierkowski, "Hybrid five-level cascaded H-bridge converter with model predictive controller," 2016 IEEE International Power Electronics and Motion Control Conference (PEMC), Varna, 128-132 (2016).

[16] M. Vasquez, J. Pontt, and J. Vargas, "Predictive control algorithm technique with reduced number of calculation for asymmetric multilevel converter with floating cells," 2015 IEEE International Conference on Industrial Technology (ICIT), Seville, 1129-1135 (2015).

[17] M. Vásquez, J. Pontt, and J. Vargas, "Predictive control of an asymmetric cascaded multilevel inverter with a single DC source," IECON 2013 - 39th Annual Conference of the IEEE Industrial Electronics Society, Vienna, 6305-6310 (2013).

[18] S. Vazquez et al., "Model predictive control: A review of its applications in power electronics," IEEE Industrial Electronics Magazine 8 (1), 16-31, (2014).

[19] J. Rodriguez et al., "State of the Art of Finite Control Set Model Predictive Control in Power Electronics," in IEEE Transactions on Industrial Informatics 9 (2, 1003-1016, May 2013.

[20] P. Cortes, M.P. Kaźmierkowski, R.M. Kennel, D.E. Quevedo, and J. Rodriguez, "Predictive Control in Power Electronics and Drives," in IEEE Transactions on Industrial Electronics 55 (12, 4312-4324, Dec. 2008.

[21] J. Rodriguez and P. Cortes, Predictive Control of Power Converters and Electrical Drives, IEEE-press-Wiley, $1^{\text {st }}$ ed. Chichester U.K, 2012.

[22] S. Kouro, P. Cortes, R. Vargas, U. Ammann, and J. Rodriguez, "Model Predictive Control - A Simple and Powerful Method to Control Power Converters," in IEEE Transactions on Industrial Electronics 56 (6, 1826-1838, June 2009. 